Note

\title{
Detection of the Helicobacter pylori dupA gene is strongly affected by the PCR design
}

\author{
Amin Talebi Bezmin Abadi a , Ruud J.L.F. Loffeld ${ }^{\mathrm{b}}$, Ashandra C. Constancia ${ }^{\mathrm{a}}$, \\ Jaap A. Wagenaar ${ }^{\text {c }}$, Johannes G. Kusters ${ }^{\text {a,* }}$ \\ a Department of Medical Microbiology, University Medical Center Utrecht, Utrecht, The Netherlands \\ b Zaandam Department of Internal Medicine, Zaans Medical Center, Zaandam, The Netherlands \\ c Department of Infectious Diseases and Immunology, Faculty of Veterinary Medicine, University of Utrecht, Utrecht, The Netherlands
}

\section{A R T I C L E I N F O}

\section{Article history:}

Received 17 April 2014

Received in revised form 18 July 2014

Accepted 23 July 2014

Available online 13 August 2014

\begin{abstract}
A B S T R A C T
The Helicobacter pylori virulence gene dupA is usually detected by PCR, but the primer binding sites used are highly variable. Our newly designed qPCR against a conserved region of $d u p A$ was positive in $64.2 \%$ of 394 clinical isolates while the positivity rate of the commonly used PCRs ranged from $29.9 \%$ to $37.8 \%$.
\end{abstract}

(c) 2014 Elsevier B.V. All rights reserved.

\section{Keywords:}

Helicobacter pylori

dupA

Primer sets

Infection with the human pathogen Helicobacter pylori can result in gastroduodenal disorders, ranging from chronic gastritis to peptic ulcer and gastric cancer (Kusters et al., 2006). Lu et al. described the duodenal ulcer promoter gene A ( $\operatorname{dupA}$ ) to be associated with $\mathrm{H}$. pylori induced ulcer formation (Lu et al., 2005). Several reports confirmed these associations, but others do not find any associations (Abadi et al., 2012; Arachchi et al., 2007; Gomes et al., 2008; Hussein, 2010; Queiroz et al., 2011). Takahashi et al. (2013) pointed out considerable sequence variation between $\operatorname{dupA}$ genes and claimed that only a specific allele (the intact long-type dupA) is associated with ulcer induction, but their evidence still (partially) relied on dupA PCR. Given the high degree of sequence variation within dupA one might argue that this might result in primer mismatches leading to erroneous PCR results. The aim of this study was to determine the effect of an improved PCR design on the detection of $H$. pylori dupA.

From a collection of all $H$. pylori strains cultured from patients that had consulted the Zaans Medical Center, Zaandam, The Netherlands, between 2005 and 2007 we selected the first 400 strains. DNA was isolated by standard automated DNA extraction using the MagNA Pure 96 DNA (Roche Diagnostics, Almere, the Netherlands). All PCR reactions always included the fully sequenced reference strains J99 and 26695 (ATCC 700824 and 700392 respectively) as positive and negative controls, respectively. To confirm the $H$. pylori nature and to check for

\footnotetext{
* Corresponding author at: Department of Medical Microbiology, University Medica Center Utrecht, Heidelberglaan 100, 3584 CX Utrecht, The Netherlands. Tel.: + 3188 7553687; fax: + 31887555426 .

E-mail address: h.kusters@umcutrecht.nl (J.G. Kusters).
}

the quality of the isolated DNA a PCR reaction with the $H$. pylori specific EHC-U/L PCR was performed (Li et al., 1995). From 6/400 strains we could not obtain a ECHC-U/L PCR product, indicating insufficient DNA quality and/or PCR inhibition, leaving $394 \mathrm{H}$. pylori strains.

A PCR targeting a conserved area of $\operatorname{dupA}$ were designed based on an alignment of all 221 dupA gene sequences present in the NCBI DNA database as of January 2013 (Table 1). A Primer-Blast analysis (http://www.ncbi.nlm.nih.gov/tools/primer-blast/) predicted that these primers would detect $220 / 221$ of the NCBI database sequences that contain the corresponding fragment. During the revision we were asked to perform a similar analysis for the other PCR reactions but as the annealing temperature of these reactions is not standard we had to perform a manual analysis. This predicted an in silico positivity rate for the jhp0917, jhp0918, dupA, and AR-dupA PCR of 65.9\%, 33.5\%, $26.3 \%$, and $98.6 \%$, respectively (Table 1 ). Considering that $254 / 379$ (67.0\%) of the full H. pylori genomes in the NCBI database carry a dupA gene the ratios of dupA positive PCRs observed among the 396 strains are in line with these predictions (Table 1). The jhp0918 PCR showed the lowest dupA detection rate (29.9\%) while the newly designed $A R$ dupA PCR had the highest positivity rate. It is unlikely that the increased dupA detection rate is a consequence of this being a real time PCR because when the qPCR products were analyzed on a gel they had similar band intensities as the other PCRs. All four PCR assays detected a different subset of strains with 30/394 (7.6\%) of the strains being only positive in the AR-dupA PCR. Sequence analysis of these 30 exclusively AR-dupA PCR products confirmed that they actually represented true dupA positives. The jhp0917 PCR was positive in 149/394 (37.8\%) of the samples and the jhp0918 PCR in 118/394 (29.9\%). Using the 
Table 1

Details of PCR assays used in the current study.

\begin{tabular}{|c|c|c|c|c|c|c|c|c|}
\hline \multirow[t]{2}{*}{ PCR name } & \multicolumn{3}{|c|}{ Oligonucleotide characteristics $^{\mathrm{a}}$} & \multirow{2}{*}{$\begin{array}{l}\text { PCR annealing } \\
\text { temperature }^{\text {b }}\end{array}$} & \multirow{2}{*}{$\begin{array}{l}\text { Size of PCR } \\
\text { fragment }\end{array}$} & \multirow{2}{*}{$\begin{array}{l}\text { Fraction of dupA } \\
\text { in NCBI predicted } \\
\text { to be PCR positive }\end{array}$} & \multirow{2}{*}{$\begin{array}{l}\text { Actual dupA PCR } \\
\text { positives in } 394 \\
\text { Dutch isolates }\end{array}$} & \multirow[t]{2}{*}{ Original PCR design } \\
\hline & Orientation & Oligonucleotide composition & $\operatorname{Tm}^{\mathrm{c}}$ & & & & & \\
\hline \multirow[t]{2}{*}{ jhp0917 } & Fw & 5'-TGGTTTCTACTGACAGAGCGC-3' & $60.3^{\circ} \mathrm{C}$ & $59{ }^{\circ} \mathrm{C}$ & 307 bp & $118 / 179(65.9 \%)$ & $149(37.8 \%)$ & Lu et al. (2005) \\
\hline & Rev & 5'-AACACGCTGACAGGACAATCTCCC-3' & $64.9^{\circ} \mathrm{C}$ & & & & & \\
\hline \multirow[t]{2}{*}{ jhp0918 } & Fw & 5'-CCTATATCGCTAACGCGCGCTC-3' & $63.8^{\circ} \mathrm{C}$ & $58^{\circ} \mathrm{C}$ & 276 bp & $69 / 206(33.5 \%)$ & $118(29.9 \%)$ & Lu et al. (2005) \\
\hline & Rev & 5'-AAGCTGAAGCGTTTGTAACG-3' & $57.3^{\circ} \mathrm{C}$ & & & & & \\
\hline \multirow[t]{2}{*}{$\operatorname{dupA}$} & Fw & 5'-TAAGCGTGATCAATATGGAT-3' & $51.8^{\circ} \mathrm{C}$ & $56{ }^{\circ} \mathrm{C}$ & 350 bp & $59 / 224(26.3 \%)$ & $132(33.5 \%)$ & Nguyen et al. (2010) \\
\hline & Rev & 5'-TGGAACGCCGCATTCTATTA-3' & $57.4{ }^{\circ} \mathrm{C}$ & & & & & \\
\hline \multirow[t]{3}{*}{ AR-dupA } & Fw & 5'-CATGGCGTTTCAAAAAATATCTCAA-3' & $57.4{ }^{\circ} \mathrm{C}$ & $60{ }^{\circ} \mathrm{C}$ & 112 bp & $284 / 288(98.6 \%)$ & $253(64.2 \%)$ & Current study \\
\hline & Rev & 5'-TTCATCAGTATCTTTTGTGGGGTA-3' & $57.6{ }^{\circ} \mathrm{C}$ & & & & & \\
\hline & Probe & FAM-GGCAACCTTTCTCAAGTGATTATC-BBQ & $58.1{ }^{\circ} \mathrm{C}$ & & & & & \\
\hline
\end{tabular}

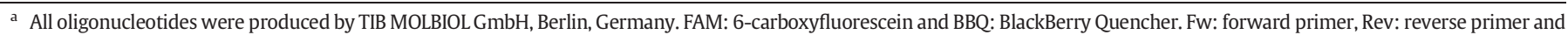
Probe: hydrolysis probe.

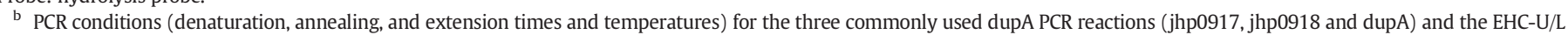

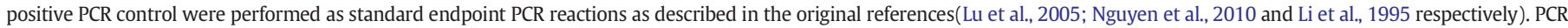

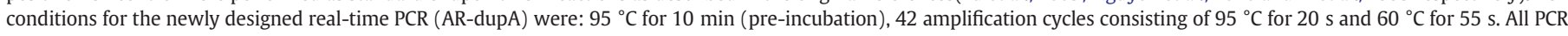
amplification reactions were performed in a Roche Light Cycler 480 II (Roche Diagnostics, Almere, the Netherlands).

c Tm of primers was calculated with Primer-Blast (http://www.ncbi.nlm.nih.gov/tools/primer-blast/) using the default settings of the program.

d All sequences spanning the jhp0917, jhp0918, dupA, and AR-dupA PCR products were retrieved from NCBI database on June 30th 2014. Fraction represents the total number of predicted

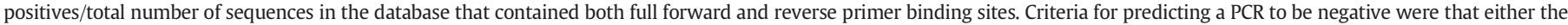

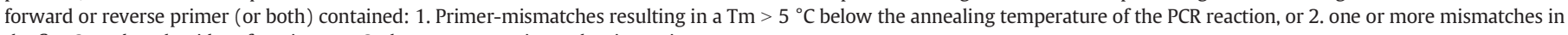
the five $3^{\prime}$ end nucleotides of a primer, or 3 . three or more mismatches in a primer.

recommendation of the original designers of the jhp0917 and jhp0918 PCRs to report the dupA status only when both the jhp0917 and jhp0918 PCRs were concordant only for 254/394 isolates (64.4\%) a dupA status could be obtained resulting in a combined dupA positivity rate of $41 / 254$ (16.1\%).

The presence of $\operatorname{dupA}$ is considered a true virulence factor with no linkage to other classical virulence factors like $\operatorname{cag} A, v a c A$, and ice $A$ (Yamaoka, 2012). However not all agree that the presence of dupA is associated with duodenal ulcers (Arachchi et al., 2007; Argent et al., 2007; Imagawa et al., 2010). As far as we know no-one has actually tested the technical limitations of the PCR assays used to detect the dupA status as a potential reason for these discrepant results. H. pylori is a genetically variable bacterium and especially at the plasticity region where the dupA gene is located is known to display substantial genomic diversity (Sugimoto et al., 2012). An in silico evaluation of the dupA gene sequences from the public DNA databases revealed significant mismatches of the different dupA primers that have been used in the published studies (Table 1). Indeed the prevalence of dupA among the $H$. pylori strains was significantly higher when using a newly designed primer set that targeted conserved areas of the dupA gene, indicating that the dupA PCR assays that have been used in the published studies probably missed some dupA positive isolates. According to our in silico prediction our PCR will detect most (98.6\%) of the dupA genes and this seems to be confirmed by the findings in our population; it is not unthinkable that it may miss specific dupA variants present in other geographical areas. In conclusion, our findings suggest that previous results on the increased prevalence of $\operatorname{dup} A$ in patients suffering from $H$. pylori induced ulceration should be interpreted with caution. More likely these papers reported the association of a specific dupA allele instead of the actual presence of the dupA gene. Thus rather than disputing or confirming the association between the presence of $d u p A$ and different gastroduodenal diseases these reports tested a relationship between a specific $\operatorname{dupA}$ allele and disease. Since various primer sets were used these different PCR assays probably tested for different dupA alleles and can thus not be compared to each other. Unfortunately, we do not have clinical data related to the strains from our collection, thus we cannot check the association between the specific disease outcome and a positive dupA PCR. For other $H$. pylori virulence factors such as $v a c A$ it is not the presence of the vacA gene but rather the presence of specific alleles $\left(s_{1} / s_{2}, m_{1} / m_{2}\right)$ that is associated with a different risk on inducing $H$. pylori associated disease (Atherton et al., 1999). The challenge would be to identify these disease specific dupA alleles and to design allele specific primers for their detection.

\section{References}

Abadi, A.T., Taghvaei, T., Wolfram, L., Kusters, J.G., 2012. Infection with Helicobacter pylori strains lacking dupA is associated with an increased risk of gastric ulcer and gastric cancer development. J. Med. Microbiol. 61, 23-30.

Arachchi, H.S., Kalra, V., Lal, B., et al., 2007. Prevalence of duodenal ulcer-promoting gene (dupA) of Helicobacter pylori in patients with duodenal ulcer in North Indian population. Helicobacter 12, 591-597.

Argent, R.H., Burette, A., Miendje, Deyi V.Y., Atherton, J.C., 2007. The presence of dupA in Helicobacter pylori is not significantly associated with duodenal ulceration in Belgium, South Africa, China, or North America. Clin. Infect. Dis. 45, 1204-1206.

Atherton, J.C., Sharp, P.M., Cover, T.L., et al., 1999. Vacuolating cytotoxin (vacA) alleles of Helicobacter pylori comprise two geographically widespread types, $\mathrm{m} 1$ and $\mathrm{m} 2$, and have evolved through limited recombination. Curr. Microbiol. 39, 211-218.

Gomes, L.I., Rocha, G.A., Rocha, A.M., Soares, T.F., Oliveira, C.A., Bittencourt, P.F., Queiroz, D.M., 2008. Lack of association between Helicobacter pylori infection with dupApositive strains and gastroduodenal diseases in Brazilian patients. Int J Med Microbiol. 298, 223-230.

Hussein, N.R., 2010. The association of dupA and Helicobacter pylori-related gastroduodenal diseases. Eur. J. Clin. Microbiol. Infect. Dis. 29, 817-821.

Imagawa, S., Ito, M., Yoshihara, M., Eguchi, H., Tanaka, S., Chayama, K., 2010. Helicobacter pylori dupA and gastric acid secretion are negatively associated with gastric cancer development. J. Med. Microbiol. 59, 1484-1489.

Kusters, J.G., van Vliet, A.H., Kuipers, E.J., 2006. Pathogenesis of Helicobacter pylori infection. Clin. Microbiol. Rev. 19, 449-490.

Li, C., Musich, P.R., Ha, T., Ferguson, D.A., Patel, N.R., Chi, D.S., Thomas, E., 1995. High prevalence of Helicobacter pylori in saliva demonstrated by a novel PCR assay. J. Clin. Pathol. 48, 662-666.

Lu, H., Hsu, P.I., Graham, D.Y., Yamaoka, Y., 2005. Duodenal ulcer promoting gene of Helicobacter pylori. Gastroenterology 128, 833-848.

Nguyen, L.T., Uchida, T., Tsukamoto, Y., Kuroda, A., Okimoto, T., Kodama, M., Moriyama, M., 2010. Helicobacter pylori dupA gene is not associated with clinical outcomes in the Japanese population. Clin. Microbiol. Infect. 16, 1264-1269.

Queiroz, D.M., Moura, S.B., Rocha, A.M., Costa, R.F., Anacleto, C., Rocha, G.A., 2011. The genotype of the Brazilian dupA-positive Helicobacter pylori strains is dupA1. J. Infect. Dis. 203, 1033-1034.

Sugimoto, M., Watada, M., Jung, S.W., Graham, D.Y., Yamaoka, Y., 2012. Role of Helicobacter pylori plasticity region genes in development of gastroduodenal diseases. J. Clin. Microbiol. 50, 441-448.

Takahashi, A., Shiota, S., Matsunari, O., Watada, M., Suzuki, R., Nakachi, S., Kinjo, N., Kinjo, F. Yamaoka, Y., 2013. Intact long-type dupA as a marker for gastroduodenal diseases in Okinawan subpopulation, Japan. Helicobacter 18, 66-72.

Yamaoka, Y., 2012. Pathogenesis of Helicobacter pylori-related gastroduodenal diseases from molecular epidemiological studies. Gastroenterol. Res. Pract. 2012, 37150-37153. 